\title{
O ROMANCE HISTÓRICO E BIOGRÁFICO DE ANA MIRANDA ${ }^{1}$
}

\author{
THE HISTORICAL AND BIGRAFICAL NOVEL OF ANA MIRANDA
}

Eunice de Morais ${ }^{2}$

\begin{abstract}
Resumo
Neste artigo, pretendemos discutir a ideia de que o caráter nacionalista dos romances históricos tradicionais permanece, porém a função revisionista da apropriação do discurso histórico, com finalidade didática e divulgadora de um ideal nacional passou a investir na revisitação crítica e reflexiva de antigos discursos, conforme observamos nos romances pós-modernos de Ana Miranda. Nos romances: Boca do inferno, A última quimera e Dias e Dias, através da revisitação da memória e do momento literário de cada poeta, há uma busca pela refiguração de uma condição nacional reemergente. Assim, no Boca do inferno, Gregório de Matos, no século XVII, revolta-se com as atitudes subservientes do Brasil em relação a Portugal, vivendo uma relação de amor e ódio com as duas pátrias, mas sendo ainda um sabiá em liberdade. Na narrativa de Dias e dias encontramos Gonçalves Dias, no século XIX, num contexto de luta pela afirmação da identidade brasileira diante da pátria-mãe, para isso é preciso superar a perda e suportar as limitações da gaiola nacionalista. De outro modo, em A última quimera, as reflexões sobre o canônico revelam uma crítica ao sistema histórico e literário brasileiro em franco reconhecimento da autonomia da literatura e da comunidade nacional brasileira que discute internamente seu processo de formação.
\end{abstract}

Palavras chaves: Romance histórico. Discursos de Nação. Ana Miranda.

\begin{abstract}
In this essay, we discuss the idea that the nationalist character of historical novels remains traditional, but the function of the appropriation of revisionist historical discourse, with didactic purpose and disclosing a national ideal began to invest in critical and reflective revisiting of old speeches, as observe in the postmodern novels of Ana Miranda. In the novels: Boca do inferno, A última quimera e Dias e Dias, by revisiting the memory and literary moment of each poet, there is a quest for refiguring of a national re-emerging condition. In the novel Boca do Inferno, Gregorio de Matos, in the XVII century, rebelled against the subservient Brazilian attitudes in relation to Portugal, living a relationship of love and hate with the two homelands, but he's a free sabiá. While in the novel Dias e dias, Gonçalves Dias, in XIX century, fights for the affirmation of a Brazilian identity in face of motherland. For that it's necessary to overcome the lost of colonial paternalism and support the limitations of the nationalistic bird cage. In other hand, in A última quimera the reflections about the canonic revel a criticism about the Brazilian historic-literary system. In a great recognition of the autonomy of the literature and the Brazilians national community which argues its own formation process internally.
\end{abstract}

Keywords: Historical Novel. Nation Discourses. Ana Miranda.

\footnotetext{
${ }^{1}$ Artigo apresentado no VI SEL (2012), organizado pela UNESP - Assis/SP.

${ }^{2}$ Doutora em Letras. Professora do Departamento de Letras Vernáculas - Universidade

Estadual de Ponta Grossa - DELET/UEPG. E-mail: nicemorais@gmail.com
} 
A proposta deste trabalho é desenvolver uma investigação sobre os romances históricos Boca do Inferno (1989), A última quimera (1995) e Dias e dias (2002), de Ana Miranda, que parecem discutir, através da metaficção, os discursos nacionalistas da literatura brasileira pelo processo de apropriação e questionamento destes mesmos discursos. Consideramos que, nesses romances históricos discute-se, além do aspecto humano dos poetas, a sua inserção no contexto histórico da produção literária brasileira. E significam, por si só, uma busca pela reapresentação da identidade nacional, investindo em discutir e questionar outros discursos.

No romance Boca do inferno, Gregório de Matos está tão integrado ao seu meio social e político que o espaço e o tempo parecem personificados no retrato do poeta. É como se o narrador tivesse buscado nos registros históricos sobre a cidade, nos costumes populares e na política da Bahia a confirmação do discurso denunciador e reivindicatório do poeta. O que faz transparecer na narrativa a construção de uma personagem representativa dos ideais estéticos do movimento Barroco, sendo ela também imagem especular do meio social brasileiro daquele momento, embora de origem e formação intelectual portuguesa. O narrador é um ser que olha diacronicamente para o passado através da história.

Em A última quimera, a presença de Augusto dos Anjos se dá pela memória de um amigo que de tão próximo permite-se a onisciência narrativa. O narrador, contemporâneo de Augusto, compartilha alguns episódios da vida do poeta e por vezes se assemelha a um outro “eu” do mesmo Augusto. O espelho aqui é individual e nos parece invertido ao refletir uma imagem que se define na memória e no desejo do poeta do reconhecimento de sua literatura que se realiza postumamente. O narrador é um ser que olha para o passado como testemunha participante do narrado.

Em Dias e Dias, a presença de Gonçalves Dias se revela no amor platônico de Feliciana. Atravessado pela "Canção do exílio", o romance põe uma personagem narradora, tipicamente brasileira e romântica, a sentir saudades do poeta e exilada de suas pretensões amorosas. É a terra das palmeiras e dos sabiás a idealizar romanticamente o poeta. A narradora é protagonista de seu próprio tempo, na medida em que revela ser a personificação da saudade do poeta ausente.

O que podemos perceber, a partir das análises dos romances de Ana Miranda, é o quanto a focalização da narrativa sobre o contexto social e ideológico de cada momento histórico vivido pelos poetas faz transparecer a complexidade das opções políticas e ideológicas de cada um deles. E, ao mesmo tempo, o quanto estas opções fazem parte de uma lógica contextual e cultural dentro dos processos de formação, afirmação e reafirmação da condição nacional. A leitura que fazemos dos romances revela outras fronteiras marcadas pelo 
contexto espacial e temporal, mas que delineiam, de certo modo, a revisitação dos discursos de nação que os poetas, inseridos em seu contexto, representam. Esta revisitação, por si só, já indica a permanência e importância do tema.

Se os interesses de Ana Miranda, ao projetar os romances, percorrem os caminhos da linguagem dos poetas, a discussão sobre o caráter nacional da literatura passa também pelo mesmo caminho. Assim, apropriar-se do estilo e da linguagem destes poetas significa apropriar-se dos discursos de nação, ou mesmo de pertencimento a determinada "comunidade imaginada”, que estes poetas representaram no curso da história da literatura brasileira. Além disso, nos parece também, significa propor que, no presente, eles participam de uma espécie de mosaico discursivo sobre o qual se desenvolvem as reflexões da autora e de seus leitores.

O desenvolvimento das análises dos romances Boca do inferno, A última quimera e Dias e dias, que aqui apresentamos de forma bastante abreviada, confirma que a composição dos mesmos dá-se pela assimilação intertextual ou transtextual que não visa à destruição semântica, mas a certo deslocamento discursivo entre o texto ou obra parodiada e o parodiador. Além disso, o “alvo” da paródia, o texto parodiado, não se encontra mais sob ataque, não é mais achincalhado pelo texto parodiador. O estilo e o discurso são apropriados através da paródia moderna com objetivo frequente de dar “continuidade” ou de homenagear os grandes estilos do passado. (HUTCHEON, 1991, p. 88). A paródia moderna, conceito definido por Hutcheon como "repetição com diferença. Está implícita uma distanciação crítica entre o texto em fundo a ser parodiado e a nova obra que incorpora, distância geralmente assinalada pela ironia” (HUTCHEON, 1989, p. 48), distancia-se do pastiche pois, em geral, ele pede a "permanência dentro do mesmo gênero que o seu modelo” (HUTCHEON, 1989, p. 55). Por outro lado, ao considerar o jogo transtextual existente nas obras em estudo, concordamos com Hutcheon que a realização desse jogo depende de um leitor e implicitamente de um autor, contrariando a perspectiva de G. Genette que, de acordo com a pesquisadora citada, rejeita a dimensão hermenêutica do texto. Justificamos, assim, a utilização do conceito de paródia moderna no desenvolvimento destas análises.

Revisitar a história de representantes da história da literatura brasileira significa revisitar modos de expressão da condição nacional. A maneira como estas expressões são refiguradas nos romances em análise aqui, nos leva a refletir sobre aspectos da história da literatura nacional, bem como das “comunidades imaginadas” (ANDERSON, 2008) em cada momento histórico narrado. O Brasil de Gregório de Matos, Augusto dos Anjos e Gonçalves Dias são comunidades imaginadas que participam ou são constituintes da comunidade imaginada que é o Brasil do presente. Ana Miranda volta-se para os representantes nacionais inscritos na 
historicidade, não para exaltá-los como heróis nacionais, mas para integrá-los à memória política e social do país. O conceito de nação expresso e marcado pela territorialidade é substituído por um conceito marcado pelo aspecto cultural inscrito na história das mentalidades de cada período narrado. Parece-nos que importa para Ana Miranda olhar a nação e a literatura nacional brasileira por suas particularidades históricas e culturais, inseridas em contextos transitórios, momentos de incertezas e de intenso movimento social. A partir destas particularidades é que poderíamos visualizar o mosaico histórico-cultural da condição nacional brasileira.

Através da revisitação da memória e do momento literário de cada poeta, há, nos romances de Ana Miranda, uma busca pela refiguração de uma condição nacional reemergente. Assim, no romance Boca do inferno, Gregório de Matos, no século XVII, revoltase com as atitudes subservientes do Brasil em relação a Portugal, vivendo uma relação de amor e ódio com as duas pátrias, mas livre para exercitar ambiguidades e contrastes exasperando a ambas. Na narrativa de Dias e dias encontramos Gonçalves Dias, no século XIX, num contexto de luta pela afirmação da identidade brasileira diante da pátria-mãe, para isso é preciso superar a perda e suportar as limitações da gaiola nacionalista. De outro modo, em A última quimera, as reflexões sobre o canônico revelam uma crítica ao sistema histórico e literário brasileiro em franco reconhecimento da autonomia da literatura e da comunidade nacional brasileira que discute internamente seu processo de formação.

Entendemos, portanto que o caráter nacionalista do romance histórico permanece, porém a função revisionista da apropriação do discurso histórico com fins didáticos e de divulgação de um ideal nacional passou a investir na revisitação crítica e reflexiva de antigos discursos. A finalidade didática atualiza-se na medida em que a narrativa atrela-se a teorias contemporâneas de recepção e construção textual, engendradas no contexto da pósmodernidade. O grau de compreensão e de inter-relação entre o leitor e o texto destes romances de Ana Miranda depende da capacidade do leitor de inferir, de entrar no jogo paródico proposto por eles. Quanto ao ideal nacional que parece estar inscrito nos romances de Ana Miranda, ficamos aqui com uma síntese apresentada por Homi Bhabha do pensamento de Hannah Arendt sobre o conceito moderno de nação:

A sociedade de nação no mundo moderno é aquele reino curiosamente híbrido, onde interesses privados assumem significância pública e os dois reinos unem-se continuamente e imprecisamente como ondas no fluxo interminável da própria vida. (ARENDTapud BHABHA, 1990.) [Tradução nossa]. 
Assim, os romances históricos de Ana Miranda vêm confirmar que o "fim da era nacionalista” (ANDERSON, 2008, p. 28) parece mesmo ainda muito distante.

\section{Boca do Inferno: desconcerto nativista}

Gregório de Matos, no romance, é expressão tanto do colonizador, por formação, quanto do colonizado, pela experiência vivida. É neste sentido que o poeta é um ex-cêntrico que se identifica "com o centro ao qual aspira, mas que lhe é negado" (HUTCHEON, 1991, p.88). Ou seja, o poeta se identifica com o poder maior que está na Europa e, por sua formação intelectual europeizada, aspira a este poder que, no entanto, lhe é negado e só será concedido oficialmente no século XIX, quando interesses históricos e literários permitirem. (CALMON, 1983, p. 212-217). Segundo o historiador Pedro Calmon, em 1713 o poeta Tomaz Pinto Brandão foi o primeiro a lembrar Gregório de Matos, imitando-lhe o estilo e mais tarde Nuno Marques Pereira, na segunda parte d'O Peregrino da América, cita-o na relação dos poetas da cidade ao lado de Eusébio de Matos. Porém, não o mencionou Rocha Pita na História da América Portuguesa por motivos assumidos pelo historiador do século XVIII: "não lhe perdoaria a rima de mim...”. A narrativa de Calmon deixa claro que, apesar da poesia de Gregório de Matos não ter, no século XVIII, subido “a dignidade dos prelos, caíra no luxo das livrarias, delas saltando para a tradição popular”.

A visão pessimista em relação ao futuro da Cidade da Bahia e a imagem pejorativa que o poeta constrói são antes fruto do desejo de edificação de uma imagem moral da cidade. É presente o desejo do poeta de que, através da crítica, ocorram mudanças, ainda que estas mudanças se deem no sentido de uma aproximação aos costumes e crenças europeias. Não há intenção meramente destrutiva, no sentido de que a Cidade da Bahia não represente nada (em termos de identidade) nem para o poeta, nem para o Brasil, por ver-se dominada pelas leis ou, ao contrário, por não se deixar dominar totalmente pela cultura de Portugal. Ou seja, o próprio posicionamento do poeta em relação à Cidade da Bahia é paradoxal, pois ao criticar as atitudes da população ele, ao mesmo tempo, critica a exploração mercantilista feita por Portugal ${ }^{3}$. Ao mostrar como os vícios aqui se tornam virtudes, comprova a ausência do domínio português no que diz respeito aos aspectos culturais em formação. O que valia como

\footnotetext{
3 O melhor exemplo desta crítica é o poema "Triste Bahia", que fala das transformações ocorridas na cidade devido à chegada da "máquina mercante" que a fez dar "tanto açúcar excelente pelas drogas inúteis". Deste modo, o poeta coloca os mercadores como o primeiro móvel da ruína da cidade.
} 
virtude na Europa, nem sempre era possível ser conservado numa terra que os olhos do rei alcançavam apenas através de cartas.

Apesar de ter formação intelectual aos moldes portugueses, Gregório de Matos reconhece a brasilidade, portanto, pelos vícios vistos como virtudes. Considerando que uma não-identidade é também uma forma de identidade, ou seja, o fato de não se identificar totalmente com o "espírito humano" ${ }^{4}$ europeu abre a possibilidade de formação de um novo espírito não menos humano que o imposto pelo colonizador e durante muito tempo aceito pelo colonizado. Assim, a formação intelectual e o ativismo político e social de Gregório de Matos o fazem oscilar, num movimento pendular, entre duas identidades e duas culturas: a colonial e a do europeu e, assim, pé lá e pé cá é que ele melhor representa, antecipadamente, este espírito multicultural que definirá o homem brasileiro, a partir do início do processo de construção da identidade nacional, no século XIX.

O movimento pendular, apresentado acima, se concretiza em atos e palavras, pois o poeta está dividido entre uma figura que observa a cidade através de uma janela e a descreve e outra que é parte desta cidade circulando por seus becos, prostíbulos, palácios e igrejas. Essa duplicidade de Gregório de Matos é refiguração paródica daquela apresentada estilisticamente em sua obra poética e possibilita a construção do personagem em sua complexidade humana, característica do espírito barroco que se instalava no Brasil, adequando-se ao contexto e à noção de mistura racial e cultural que se instalará postumamente. Lembramos aqui que tanto no início do século XIX quanto no início do século XX a noção de mistura é o que define o jeito de ser brasileiro. Em Casa grande e senzala, de Gilberto Freire, a mistura ou a miscigenação é apresentada como eufórica, segundo Fiorin:

O Brasil celebra a mistura da contribuição de brancos, negros e índios na formação da nacionalidade, exaltando o enriquecimento cultural e a ausência de fronteiras de nossa cultura. De nosso ponto de vista, o misturado é completo; o puro é incompleto, é pobre. (FIORIN, p. 120).

Assim, entendendo a formação da identidade nacional como formação discursiva que se constitui dialogicamente (BAKHTIN, 1992, p. 319), vemos a personagem Gregório de Matos, no romance, como espaço de transição e diálogo inter-discursivo que antecipa ou prevê o homem brasileiro do século XIX.

\footnotetext{
4 SANTIAGO, Silviano. Atração do mundo (políticas de Globalização e de Identidade na moderna Cultura brasileira). Unas Lecture, Berkeley, out/nov. 1995. Disponível em: http://www.ufrj.br/paccequipesilviano.html. A expressão é de Joaquim Nabuco e sintetiza a ideia de que "O espírito humano, que é um só e terrivelmente centralista, está do outro lado do Atlântico”.
} 
Na narrativa, as apropriações de trechos dos poemas de Gregório de Matos constituem uma espécie de metonímia, em que não se desconsidera o todo dos textos, mas também não o apresenta. Se na biografia de Pedro Calmon, a qual tomamos como exemplo, os poemas são ilustrativos do estilo e do posicionamento ideológico do poeta, incorporados à narrativa romanesca eles adquirem estatuto pragmático, mundano, tornam-se fala, descrição de espaços, impregnando a narrativa com o estilo do poeta. Os versos de Gregório de Matos são o próprio poeta desfeito em linguagem.

Assim, o nativismo de Gregório de Matos ou o seu sentimento de pertencimento à colônia está, no romance de Ana Miranda, inscrito pela relação ser, espaço e tempo, sendo o espaço cultural territorializado elemento definidor do ser nacional em processo de construção discursiva. Apropriações de poemas que descrevem criticamente a Cidade da Bahia revelam este ponto de vista. Deste modo, quando no romance encontramos:

\footnotetext{
‘Esta cidade acabou-se’, pensou Gregório de Matos, olhando pela janela do sobrado no terreiro de Jesus. 'Não é mais a Bahia. Antigamente havia muito respeito. Hoje, até dentro da praça, nas barbas da infantaria, nas bochechas dos granachas, na frente da forca fazem assaltos à vista'. (MIRANDA, 1999/1989, p. 13).
}

O espaço do romance incorpora aspectos culturais e morais impostos pelo colonizador, mas sem abandonar totalmente as características de origem. Há, com isso, uma espécie de unificação ou congruência entre ser e espaço, os quais são marcados ideologicamente pelo tempo histórico narrado. A cidade e Gregório de Matos são figuras máximas que foram incorporadas ao espírito da época. A primeira por sediar tanto eventos históricos quanto a vida do poeta e a segunda por representar o sentimento do mundo barroco no Brasil. O que desencadeia esta tal representação no romance é o assassinato do alcaide Francisco Telles, fato que assinala o recorte que se faz sobre a vida do poeta e sobre a história do Brasil, para apresentar e desenvolver questionamentos e reflexões a respeito das imposições moralizantes dos colonizadores sobre os colonizados, do caráter canônico da história e da crítica literária.

A apresentação de Gregório de Matos no romance demonstra uma preocupação em dar a ele complexidade humana através de seu lugar no mundo barroco, de sua representação como figura histórica e política, através de suas descrições como indivíduo social e como artista. Essa complexidade humana, busca de romancistas e biógrafos, dá ao poeta um caráter paradoxal que é próprio do ser barroco. Portanto, Gregório de Matos é o Boca do Inferno não apenas pelas palavras que profere, mas pelo ser barroco (brasileiro e português) que 
representa. É uma entrada para desvendar a complexidade identitária que é o ser brasileiro e é esta a busca maior presente no romance enquanto representação histórica.

Para que essa caracterização se dê coerentemente, dois aspectos da estética barroca estão fortemente apresentados no romance: o Cultismo e o Conceptismo. Essas características estão entrelaçadas à forma e ao conteúdo da obra de modo a garantir o seu teor histórico, crítico, literário e biográfico. Assim como para os artistas representantes da estética barroca, o romance transmite a sensação inquietadora de que em tudo habita uma natureza dúplice. O que era apresentado pelo uso de antíteses, onde cada afirmação implicava o contrário dela mesma, o paradoxal está no romance através da personificação de Gregório de Matos. Ele é o ser que guarda o avesso daquilo que mostra e o mundo de Gregório de Matos é o resultado de um jogo feito diante do espelho.

A atualização do discurso nativista, presente na obra de Gregório de Matos, pelo romance, ocorre quando a noção de centro deixa de funcionar, na e para a narrativa, como uma realidade fixa e imutável que serve de pivô entre opostos binários, onde sempre um dos lados é privilegiado: branco/negro, homem/mulher, eu/outro, Ocidente/Oriente, colonizador/colonizado, e passa a ser considerado como uma elaboração, uma ficção, em que o “ou-ou” dá lugar ao "e-também” da multiplicidade e da diferença. O romance Boca do Inferno privilegia a multiplicidade quando, ao narrar a vida de Gregório de Matos, o faz considerando não apenas seu caráter artístico, mas também sua atividade social, política, religiosa e individual; dando a ele não a perspectiva do cânone literário, mas a do indivíduo que se posiciona ativamente contra a situação política e cultural da colônia e que, por isso, é posto à margem do sistema, tornando-se um poeta andarilho que canta o desconcerto do mundo colonial. Deste modo, o nativismo de Gregório de Matos, tal como o discute Afrânio Coutinho, está no romance como traço ideológico em questionamento. Cada fragmento de texto apropriado diz tanto sobre o contexto social e político da cidade quanto sobre os interesses individuais do poeta.

\section{A última Quimera: a nação em trânsito}

A relação do protagonista com o espaço social se dá de modo diverso em A última quimera. Neste o tempo e o contexto histórico da narrativa já não comportam o mesmo ideal. O Brasil de Augusto dos Anjos busca impor-se no contexto mundial como Estado-nação. Os antigos interesses de afirmação da condição nacional precisam ser reformulados e caminham para um processo de reafirmação ou de confirmação da autonomia e legitimidade do Estado- 
nação brasileiro. A dependência administrativa e cultural em relação a Portugal fazia vigorar, no Brasil colonial, um discurso oscilante entre a manutenção do regime e a sua crítica, porém sem pensar ainda na independência instituída quase dois séculos depois.

É interessante notar que os recortes temporais feitos por Ana Miranda para a construção narrativa dos romances fazem coincidir momentos decisivos da história social brasileira e da biografia dos poetas refigurados. Representantes da história literária brasileira, esses poetas são propostos nos romances como protagonistas e testemunhas da história social do país. Em A última quimera, Augusto dos Anjos não é comparado, nem definido pelo meio em que vive. O espaço social é diversificado, múltiplo, enquanto o poeta sofre para adaptar-se a essa diversidade. A Paraíba, o Rio de Janeiro e Leopoldina têm características próprias que o poeta vai desvelando, embora não se encaixe em nenhuma delas. Elas representam um percurso, pegadas que sinalizam os infortúnios de Augusto dos Anjos e sua visão de mundo.

Se no Boca do Inferno o narrador apropria-se dos versos do poeta, buscando neles as várias faces de Gregório de Matos e, principalmente, um perfil político e social da colônia, no A última quimera são apropriadas as correspondências de Augusto trocadas com dona Córdula, sua mãe. As cartas, tal como nos mostra Raimundo Magalhães Júnior na obra Poesia e vida de Augusto dos Anjos (1977), são documentos que registram a preocupação do poeta em relação aos acontecimentos políticos e literários de seu tempo. Ana Miranda constrói a narrativa do romance tendo estas tais cartas como fonte (além de outros textos históricos) e apropria-se de alguns trechos em que o poeta, enquanto intelectual que luta por um espaço na sociedade literária, tece comentários e opiniões sobre personagens e fatos da história do Brasil que testemunha.

O que pretendemos, neste momento, é reconhecer o potencial crítico dessas apropriações de fragmentos textuais que tratam de assuntos nacionais. Os fragmentos nem sempre são apresentados tal como são encontrados nas cartas e, por vezes, basta-lhes a transcontextualização para modificar-lhes o sentido ou mesmo a intenção primeira expressa nas cartas. Repetição com diferença crítica, justaposição de ideias é o que nos parece ocorrer em alguns momentos da construção narrativa.

O ano de 1910, quando Augusto dos Anjos muda-se para o Rio, é marcado pela disputa eleitoral entre o Marechal Hermes R. da Fonseca e Rui Barbosa pela sucessão presidencial. Ano de decisão também para Augusto, pois o agravamento da crise econômica obrigara a família a desfazer-se do Engenho do Pau D’arco, cenário de sua infância e juventude presente em suas composições poéticas. Nesse mesmo ano, casa-se com Esther Fialho e ocorre o incidente com o presidente da província, João Machado, tomando a decisão de pedir demissão 
e partir para o Rio de Janeiro. Três meses depois, continuava desempregado na capital nacional. A notícia do primeiro emprego no Rio é dada a 29 de abril de 1911 e na carta à mãe do dia 29 de maio desabafa ao falar sobre o irmão Aprígio dos Anjos que também se mudara para a capital:

\begin{abstract}
Desenvolveu ele alguns esforços, no intuito de arranjar qualquer emprego nesta capital - espécie de sereia falaciosa - pródiga unicamente em sonoridades traidoras para os que vêm aqui pela primeira vez [...] Era meu desejo que Aprígio não saísse agora do Rio de Janeiro. Todavia, em se tratando de lutar pela vida, nesse século de danação social, em que o dinheiro logrou a tiara de pontífice ubíquo, para reinar discricionariamente sobre todas as coisas, é muito de louvar o procedimento do Aprígio, saindo dessa Paraíba Madrasta, enxotadora de seus filhos, em busca de outra atmosfera mais propícia a florescer libérrimo de suas ricas aptidões de moço. [...]. (MAGALHÃES JR., 1977, p. 248).
\end{abstract}

No romance essas críticas aparecem em momentos e contextos diversos, unidas a outras críticas feitas pelo poeta em outras cartas, artigos publicados em jornal. O narrador, antes de apresentar, entre aspas, um trecho da carta, descreve os motivos da decepção do poeta.

\begin{abstract}
Uma cidade cosmopolita, mas que até então lhe parecia uma aldeia - embora houvesse muitos franceses e ingleses - repleta de injustiças sociais, um espetáculo de miseráveis ao lado de caleças, automóveis, que tornavam as ruas tristes corredores. 'O Rio de Janeiro é uma espécie de sereia falaciosa, pródiga unicamente em sonoridades traidoras para os que vêm pela primeira vez'. (MIRANDA, 2000/1995, p. 33).
\end{abstract}

A narrativa une ao enunciado da carta uma ideia comum à cultura brasileira, pois compara o Rio a uma "aldeia”, sugerindo a ausência de civilização e ressalva a presença de alguns franceses e ingleses, como presença da civilização. O que o romance faz, nos parece, é configurar no discurso do narrador e, por extensão, no de Augusto dos Anjos, o pensamento típico de uma época em que muito se valoriza o elemento europeu, que ainda constitui um modelo de civilização. A modernidade brasileira se prepara ainda para as discussões e mudanças no plano social, cultural e político.

É neste ambiente de mudanças que amadurecem os ideais que farão parte de um projeto artístico que será discutido a partir de 1922. Um projeto que valorize e proponha a redefinição da identidade nacional, reconhecendo que os moldes do nacionalismo romântico já não se enquadram no contexto social e histórico brasileiro do século XX. No romance $A$ última quimera, esta ambientação é essencial em dois sentidos: o da relação entre o ser (o poeta) e seu contexto histórico e social, que determinam a sua trajetória pessoal; e o da inscrição deste ser como peça chave para se pensar o momento de transição histórica e literária. Na citação 
acima, temos a voz do poeta endossando o clima paradoxal na capital nacional. As ruas invadidas pelo automóvel, símbolo da modernidade industrial, vistas como "tristes corredores”, tem como imagem oposta a presença dos miseráveis e a intelectualidade tacanha descrita, mais uma vez, pela voz do poeta:

Disse (Augusto) que o Rio era uma cidade que premiava as falcatruas. Os honestos, os sonhadores, eram considerados bestas idiotas. Dentre os poetas grassava o convencionalismo imbecil de Aníbal Tavares, Teófilo Pacheco, a camarilha inteligente, competindo em bovarismos com letrados de Buenos Aires e Paris. Os intelectuais só se preocupavam com futilidades, como a estátua a Eça de Queiroz. Gente como Coelho Neto, João do Rio, grandes homens da literatura, enchiam páginas e páginas das folhas com o 'assunto tão palpitante'. (MIRANDA 2000/1995, p. 33).

É Francisco de Assis Barbosa, em notas biográficas publicadas no Eu e outra poesias (1983), quem assinala o fato:

\begin{abstract}
A literatura oficial não poderia receber o Eu sem restrições. Jamais consagraria Augusto dos Anjos. Os grandes das letras continuariam a ignorar o poeta e seu livro. Em junho de 1912, o que realmente empolgava as rodas literárias era a ideia de Medeiros e Albuquerque para que se levantasse no Rio de Janeiro uma estátua a Eça de Queiroz, obra do escultor Pinto do Couto, que certamente não agradaria o criador d’O primo Basílio. Entrevista de Coelho Neto, Bilac, Alberto de Oliveira, Paulo Barreto, Felinto d'Almeida e Felix Pacheco enchiam colunas de jornais a respeito de assunto tão palpitante. (BARBOSA, 1983, p. 63).
\end{abstract}

A paródia do texto de Assis Barbosa pode ser verificada pelas alterações dos nomes dos poetas na narrativa do romance, indicando esquecimento, talvez proposital, dos mesmos. Quanto ao assunto da propriedade de uma estátua como homenagem a um escritor, o narrador parece tomar posição oposta à de Augusto dos Anjos que, segundo o mesmo, considera "uma tolice”. No último parágrafo do subcapítulo acaba por demonstrar simpatia ao caráter nostálgico e encantador da presença das estátuas em lugares públicos dizendo: “fico admirando a estátua de José de Alencar muito triste em sua cadeira de bronze; sinto vontade de acariciar suas mãos”. (MIRANDA, 2000, p.34)

A estátua de José de Alencar, escritor romântico brasileiro, é aceita pelo narrador, mas não a de Eça de Queiroz, ficcionista do Realismo português. Dois pontos de vista sobre o assunto são apresentados sem que deles se proponha uma conclusão. O tema permanece aberto para o leitor como a convidá-lo a refletir. Constitui-se nisso o traço irônico da construção paródica. O sentido do texto de Assis Barbosa é desdobrado, aberto, multiplicado, embora não destitua o sentido primeiro. O leitor, ao transitar entre os textos e seus significados reconhece a paródia e faz a ironia acontecer. 
A desilusão com o Rio de Janeiro, apresentada no romance, pelas dificuldades para publicar o $E u$, se estende ao ambiente literário e social da capital brasileira. Mas o "assunto tão palpitante” da estátua, citado por Assis Barbosa, dá-se após a publicação. A cronologia factual não é primordial à construção deste romance atravessado pela memória do narrador e, portanto, as apropriações textuais são, não raro, deslocadas espacial e temporalmente. Ou seja, das cartas para o romance; do documento para a ficção; de um registro marcado pela exatidão temporal para uma narrativa trançada pela memória e pela história.

A caracterização da Paraíba, no romance, como "Madrasta monstruosa enxotadora de seus filhos” virá como introdução à narração da partida de Augusto em direção ao Rio de Janeiro e do motivo que o fez tomar tal decisão.

\begin{abstract}
Sua partida da Paraíba - 'madrasta monstruosa enxotadora de seus filhos' - (...) foi após o desentendimento e sua enérgica reação contra a diatribe do Joque, presidente da província, admirador de Augusto e que, no entanto, agiu como se fosse seu inimigo. $\mathrm{O}$ fato foi quase uma tolice, uma dessas pequenas coisas que mudam enormemente o destino de uma pessoa. Mas para Augusto representava muito. (MIRANDA, 2000, p.112).
\end{abstract}

O motivo pessoal de Augusto dos Anjos alia-se, no mesmo capítulo do romance, a outro de caráter social: a fuga do clima provinciano para o lugar onde tudo acontece - a capital nacional. Segundo o narrador, “os jovens deixavam sua província, aos magotes, rumo à gloria cosmopolita” (MIRANDA, 2000, p.116). Vemos, assim, que os espaços onde viveu o poeta Augusto dos Anjos foram importantes para a caracterização do contexto social brasileiro da época, e as características próprias da administração política desses espaços tão diversos são o que constituem a formação individual do poeta e, ao mesmo tempo, representam o Estadonação. Referindo-se à diferença entre a Paraíba e o Rio de Janeiro narra-se que "a violenta política local não nos satisfazia, queríamos estar próximos da descontraída cidade onde tudo se decidia”. (MIRANDA, 2000, p.116) Leopoldina, “uma cidadezinha aprazível, num vale, cercada de distantes montanhas verdejantes” (MIRANDA, 2000, p. 174), era o oposto do Rio de Janeiro. Para viver em Leopoldina, segundo o narrador,

a pessoa precisa ter um caráter especial para morar num lugar como este. Primeiro, não pode gostar da solidão, a solidão é algo que só encontramos nos desertos, nas cavernas, nas grandes cidades; depois não pode gostar de sonhar, pois se sonhar acaba indo embora daqui. (MIRANDA, 2000, p. 180).

Em outro momento, acrescenta que em Leopoldina "todos os moradores têm algo em comum, talvez movimentos mais lentos, ou uma concentração no espírito; são uma gente 
contida, ingênua, eivada de pureza e paciência” (MIRANDA, 2000, p. 233). Distante da agitação política e da intelectualidade carioca, em Leopoldina, o poeta alcança maior respeito e reconhecimento. Diante da morte de Augusto, diz o padre da cidade ao narrador:

\begin{abstract}
Sabe, meu filho, esta cidade está de luto, há um grande pranto em Leopoldina, como se lhe tivessem saqueado toda prata e ouro e os vasos preciosos e os tesouros escondidos. Os príncipes e os anciãos gemem, as virgens e os jovens perderam as forças, a formosura das mulheres desapareceu, como no luto de Israel no primeiro livro dos Macabeus. Os homens se entregam ao pranto e as mulheres, assentadas sobre seu leito, derramam lágrimas. Estamos perplexos. Aqui, todos nos sentimos culpados pela morte do poeta. (MIRANDA, 2000, p. 234-235).
\end{abstract}

As descrições das cidades, como espaços sociais individualizados, constituem fases da vida de Augusto dos Anjos. Em conjunto, esses espaços dão o clima nacional do país, no início do século XX. O foco temporal do romance está sobre os anos de 1910 e 1914 e, ao pinçar alguns fatos da vida do poeta e do país, refigura momentos decisivos da biografia do poeta do hediondo e de seu país.

No soneto “Guerra”, composto depois da irrupção em agosto de 1914, da conflagração europeia que repercutiu em Leopoldina, Augusto encara o conflito, segundo Assis Barbosa, como uma expressão da Struggle for live darwiniana em escala internacional. O conteúdo do poema contrasta com a posição de seu irmão Rômulo, apresentada pela via ficcional, no romance. Uma voz mais pragmática que a de Augusto, Rômulo traz novamente a questão do pacifismo do povo brasileiro e parece sutilmente lembrar a voz solitária do poeta em outra fase mais patriótica, quando em cena aberta gritara "Viva a república", no dia 13 de maio de 1908. (MAGALHÃES JR., 1977, p.283).

O Brasil permanece numa insuportável paz, como se não fizesse parte do mundo. Algumas vezes caminhamos pela rua e ouvimos alguém gritar 'Vive la France!', mas é uma voz solitária; [...] (MIRANDA, 2000, p. 213).

E para concluir a ideia de pacifismo, Rômulo afirma que “o povo brasileiro só vai empunhar suas escopetas no dia em que o privarem de seus magníficos cigarros Vanille”. Interlocutor de Rômulo, o narrador é quem mais uma vez expressa o ponto de vista de Augusto dos Anjos. Ainda que de modo menos filosófico, o darwinismo se mostra semelhante.

A guerra toma as páginas de nossos jornais e a cabeça dos jovens arrebatados, que sonham com as batalhas, imaginam-se pilotando aeroplanos, sobrevoando cidades, despejando bombas nas catedrais dos inimigos. Metem suas imaginárias botas na lama para atravessarem campos minados, saltam sobre cercas de arame farpado, 
cavam trincheiras, atiram com canhões, enfiam baionetas nos peitos dos inimigos que muitas vezes têm o rosto de seus próprios pais ou irmãos. A Guerra, para nós, é apenas uma fantasia. (MIRANDA, 2000, p. 212).

No poema, Augusto define “Guerra é esforço, é inquietude, é ânsia, é transporte.../ É a dramatização sangrenta e dura/ Da avidez com que o espírito procura/ Ser perfeito, ser máximo, ser forte!” (MAGALHÃES JR., 1977, p. 309). A transição entre o poema e a narrativa do romance parece nos sugerir que a guerra é uma fantasia para a humanidade, mas essa é uma proposta que não se encerra no romance, se complementa com as ideias inferidas no texto poético de Augusto dos Anjos. Entre um ponto de vista filosófico e outro mais mundano o leitor trabalha com o seu horizonte de conhecimento, formula conclusões possíveis sobre o assunto aberto.

A atualização de discursos de nação ou sobre a condição nacional brasileira de cada época se dá justamente neste processo de intersecção discursiva. A narrativa provoca no leitor a relativização de discursos do passado e consequentemente dos discursos do presente inscritos nas narrativas que reconstroem ou refiguram este passado.

\section{Dias e Dias: sabiás na gaiola}

As análises empreendidas até aqui apontam para a ideia de que entender o Estado como anterior à nação, no caso brasileiro, não dá conta da complexidade do processo de construção da identidade nacional ( MAGALHÃES JR., 1977, p. 309). O romance Dias e dias (2003), de Ana Miranda, nos leva a reflexões sobre a formação da nação e do Estado nacional brasileiros, no início do século XIX. Parece-nos que a narrativa aponta para o fato de que esta formação não se dá apenas por uma "ruptura unilateral do pacto político que integrava as partes da América no Império Português” (Idem Ibidem); e que a vontade de emancipação política não equivale à constituição do Estado nacional brasileiro.

As relações entre o romance Dias e dias, de Ana Miranda, e o discurso nacionalista romântico estão sugeridos em vários momentos da narrativa do romance. Por exemplo, o relato sobre João Manuel Gonçalves Dias, pai do poeta, como um "português de Trás-osMontes, não gente daqui mesmo, não era brasileiro como minha família de militares cearenses que vieram lutar contra o coronel Fidié e acabaram ficando por aqui [...]” (MIRANDA, 2002, p. 31). A narradora, Feliciana, assinala neste trecho a inimizade entre brasileiros e portugueses, entre os que defendiam o Brasil independente e os que queriam a volta do domínio português. O pai de Gonçalves Dias lutara ao lado da resistência, comandada pelo 
Major João da Cunha Fidié, citado no poema “Ao aniversário da independência de Caxias” em que o poeta canta a força e a liberdade de Caxias. Fica assim, exposta a posição política oposta entre o pai de Feliciana e o pai de Gonçalves Dias, constituindo isso parte da contextualização histórica do romance.

Em seguida, a narradora contextualiza historicamente o ano do nascimento do poeta romântico e o seu como um tempo conturbado. Tal como Gonçalves Dias, em nota autobiográfica, a narradora associa o nascimento de ambos aos acontecimentos políticos, assumindo de forma indireta que foram profundamente marcados por eles. Nascido com a independência de sua terra, como o apresenta Lúcia Miguel Pereira, Gonçalves Dias narra seu nascimento assim:

\begin{abstract}
'As províncias do norte do Brasil foram as que mais tarde aderiram à independência do Império. Caxias, então chamada Aldeias Altas no Maranhão, foi a derradeira. A independência foi ali proclamada depois de uma luta sustentada em denodo por um bravo oficial português que ali se fizera forte. Isto teve lugar à [sic] $1^{\circ}$ de Agosto de 1823. Nasci a 10 de agosto desse ano.' (PEREIRA, 1941, p. 09). ${ }^{5}$
\end{abstract}

Enquanto que Feliciana opta por uma descrição mais social:

O tempo de nosso nascimento, Antonio em 1823 e eu em 1824, foi conturbado, Caxias já era uma comarca próspera, os portugueses desde muito antigamente tinham se estabelecido lá para negócios de comércio, retalho, exportação, importação, eles animavam a economia, tinham os cargos políticos, controlavam os negócios públicos, [...]. Um pouco antes do meu nascimento começou um tempo de pobreza, o negócio do algodão estava esboroado porque o algodão não tinha mais lugar no comércio entre os países [...] aqui se ouvia falar todo o tempo de insurgentes, movimentos nacionalistas em que conspiravam contra o rei, mas os portugueses em Caxias adoravam dom João e resistiam ao Império Independente. (MIRANDA, 2002, p. 34-35).

Observamos, portanto, que há uma mudança de focalização histórica que vai do factual para o social, mas há ainda a intenção de marcar o contexto histórico como um dos fatores determinantes na formação ideológica nacionalista do poeta. A vitória dos brasileiros será cantada pelo poeta em sua homenagem ao aniversário da independência de Caxias, a qual se encerra com os versos “Oh! Fora belo arriscar a existência em pró da pátria, / Regar de rubro sangue o pátrio solo, / E sangue e vida abandonar por ela.” (PEREIRA, 1941, p.12). A narradora e personagem, que não esconde a sua obsessão pelo poeta, cola a sua origem na dele e seu posicionamento político, ou a falta dele, é uma união de simpatias inconciliáveis.

\footnotetext{
5 A autora aponta, em nota, o “evidente engano do poeta”, pois desde 1812, quando foi elevada a vila,
} tinha Caxias o nome atual. 
Às vezes fico pensando: se não tivesse acontecido a Independência, se papai não tivesse vindo lutar contra o Fidié, se eu tivesse nascido em Fortaleza, eu nunca teria conhecido Antonio. Por isso amo secretamente o coronel Fidié e quando papai fala mal dele eu saio de perto. (MIRANDA, 2002, p. 42).

A fala de Feliciana, compreensiva dos conflitos interiores do poeta mestiço e filho natural (português), se revela também nos primeiros versos do mesmo poema Caxias (ao aniversário da independência de Caxias): “O nobre Fidié, que a antiga espada, / Do valor Português empunha hardido...”. Por outro lado, podemos inferir dessa fala que o destino de ambos se amarra ao destino e à história da nação brasileira. Os textos do poeta, assim como o contexto histórico e social do país apresentado por biografias ou pela historiografia literária brasileira atravessam o romance, imprimindo nele um aspecto de fragmento de um mosaico representativo da história de um espaço, um tempo e um ser que inscrevem o processo de formação nacional.

Gonçalves Dias é, assim, um sabiá que aprendeu a cantar na gaiola, tal como nos descreve a narradora o processo de aprisionamento do sabiá, ave que não se ajusta à prisão em gaiolas. Cercado pela crítica, bem como pelas imposições estéticas de lideranças portuguesas no meio literário, porém impulsionado pelo desejo de ser o primeiro poeta brasileiro a ganhar destaque, o poeta alcança o reconhecimento. A literatura nacional brasileira tem em Gonçalves Dias a expressão de uma identidade nacional fundada na busca pela representação do herói nacional e da cor local, que responde ao projeto nacionalista romântico.

Segundo o professor e historiador István Jancsó, os estudos históricos têm “privilegiado a formação do Estado, reconhecido brasileiro e a partir daí (em geral por inferência), admitido como nacional.” (JANCSÓ, 2009, p.2). Entendemos, portanto, que o romance segue direção contrária. Ainda segundo o professor, a emergência do Estado brasileiro se dá em meio à coexistência, no interior do que fora anteriormente a América portuguesa, de múltiplos projetos políticos, cada qual sintetizando trajetórias coletivas que, na sua particularidade, balizavam alternativas diferentes de futuro. Estes tais projetos tomavam por fundamento o passado e o presente das comunidades em que tais projetos seriam engendrados. Sendo assim, cada qual se referia a alguma realidade que, no contexto da crise geral do antigo regime, trazia em si potencialidade de tipo nacional. Diante disso, se observarmos nas manifestações contemporâneas expressões de sentimento de pertencimento ou indicando adesão a alguma comunidade imaginável como nacional, isto significa que precisamos repensar o universo das identidades coletivas, fundamentalmente devemos observar o que elas "revelam sobre a própria estruturação do novo estado e sobre o tomar corpo e forma da nova nação brasileira na 
primeira metade do século XIX”. (JANCSÓ, 2009, p. 2) A focalização da narrativa do romance Dias e dias em um contexto histórico social, no qual se inclui o poeta, nos permite visualizar o confronto entre dois aspectos da formação nacional: aqueles que queriam manter a nacionalidade portuguesa e os que queriam libertar-se dela. Refiguram essas posições o pai de Gonçalves Dias e o pai de Feliciana; como posições militares aparecem o coronel Fidié que Lúcia Miguel Pereira diz ser Major - e Lord Cochrane.

Autores de obras canônicas da literatura nacional, Gregório de Matos, Augusto dos Anjos e Gonçalves Dias viveram e imprimiram em seus textos a condição nacional brasileira do passado, representaram uma luta particular de afirmação no panorama da literatura nacional tanto quanto representam uma referência pública para além das fronteiras nacionais. Os romances de Ana Miranda, vistos em conjunto, sugerem o status processual da condição nacional da literatura bem como da sociedade brasileira. Fazer reviver, no plano ficcional, momentos importantes desse processo e as dificuldades encontradas pelos poetas que os representam, pode ter a pretensão de renovar a visão sobre a condição nacional (ou nacionalidade) através da refiguração de poetas marginalizados pelo espaço, pelo contexto histórico e literário. Quem são nossos heróis nacionais? Quem nos retratou ao mundo, marcando nossas diferenças culturais e linguísticas? É esse embate de diferenças que nos compõe. Discursos de nação surgem, nos romances, em fragmentos revisitados do eu e do outro, do lá e do cá, no passado e no presente.

\section{Referências}

ANDERSON, Benedict. Comunidades imaginadas: reflexões sobre a origem e a difusão do nacionalismo. São Paulo: Companhia das Letras, 2008.

BAKHTIN, M. Estética da criação verbal. São Paulo: Martins Fontes, 1992.

BARBOSA, Francisco de A. Notas biográficas. In: ANJOS, Augusto. Eu e outras poesias. 35. ed. Rio de Janeiro: Civilização Brasileira, 1983.

BHABHA, Homi. Narration and narration. London: Rouledge, 1990.

CALMON, Pedro. A vida espantosa de Gregório de Matos. Rio de Janeiro: Bloch, 1983.

FIORIN, J. Luis. A construção da identidade Nacional brasileira. Revista Bakhtiniana, São Paulo, v. 1, n. 1, p. 115-126, 1 o sem. 2009. Disponível no site:

<revistas.pucsp.br/index.php/bakhtiniana/> . Acesso em: mar. 2013.

HUTCHEON, L. Uma teoria da paródia. Lisboa: Edições 70, 1989.

. Teoria e política da ironia. Belo Horizonte: Ed. da UFMG, 2000. 
Poética do pós-modernismo: história, teoria e ficção. Rio de Janeiro: Imago, 1991.

JANCSÓ, István. Formação do Estado e da nação: Brasil 1780 - 1850. Disponível no site: $<$ http://www.fflch.usp.br/dh/pos/hs/images/stories/docentes/IstvanJancso/FundacaoEstadoNac ao.pdf $>$, em 09 nov. 2009. p. 02.

MAgalhães JR. Raimundo. Poesia e vida de Augusto dos Anjos. Rio de Janeiro: Civilização Brasileira, 1977.

MIRANDA, Ana. A última quimera. 3 ed. São Paulo: Companhia das Letras, 2000.

Boca do Inferno, 4. ed. São Paulo : Companhia das Letras, 1999.

Dias e Dias. São Paulo : Companhia das Letras, 2002.

PEREIRA, Lúcia Miguel. A vida de Gonçalves Dias. Rio de Janeiro: J. Olímpio, 1941.

SANTIAGO, Silviano. Atração do mundo (políticas de Globalização e de Identidade na moderna Cultura brasileira). Unas Lecture, Berkeley, out/nov. 1995. Disponível em: $<$ http://www.ufrj.br/pacc-equipesilviano.html $>$. 